San Jose State University

SJSU ScholarWorks

Master's Theses

Master's Theses and Graduate Research

1999

\title{
Remote versus laboratory usability evaluations with static versus interactive graphical user interfaces
}

Naomi Ruth Jobrack-McDaniel

San Jose State University

Follow this and additional works at: https://scholarworks.sjsu.edu/etd_theses

\section{Recommended Citation}

Jobrack-McDaniel, Naomi Ruth, "Remote versus laboratory usability evaluations with static versus interactive graphical user interfaces" (1999). Master's Theses. 1827.

DOI: https://doi.org/10.31979/etd.8sma-ps9y

https://scholarworks.sjsu.edu/etd_theses/1827

This Thesis is brought to you for free and open access by the Master's Theses and Graduate Research at SJSU ScholarWorks. It has been accepted for inclusion in Master's Theses by an authorized administrator of SJSU ScholarWorks. For more information, please contact scholarworks@sjsu.edu. 


\section{INFORMATION TO USERS}

This manuscript has been reproduced from the microfilm master. UMI films the text directly from the original or copy submitted. Thus, some thesis and dissertation copies are in typewriter face, while others may be from any type of computer printer.

The quality of this reproduction is dependent upon the quality of the copy submitted. Broken or indistinct print, colored or poor quality illustrations and photographs, print bleedthrough, substandard margins, and improper alignment can adversely affect reproduction.

In the unlikely event that the author did not send UMI a complete manuscript and there are missing pages, these will be noted. Also, if unauthorized copyright material had to be removed, a note will indicate the deletion.

Oversize materials (e.g., maps, drawings, charts) are reproduced by sectioning the original, beginning at the upper left-hand corner and continuing from left to right in equal sections with small overlaps. Each original is also photographed in one exposure and is included in reduced form at the back of the book.

Photographs included in the original manuscript have been reproduced xerographically in this copy. Higher quality $6 " \times 9$ " black and white photographic prints are available for any photographs or illustrations appearing in this copy for an additional charge. Contact UMI directly to order.

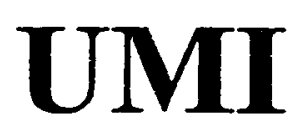

A Bell \& Howell Information Company 300 North Zeeb Road, Ann Arbor MI 48106-1346 USA

$313 / 761-4700 \quad 800 / 521-0600$ 



\section{NOTE TO USERS}

This reproduction is the best copy available

UMI 

REMOTE VERSUS LABORATORY USABILITY EVALUATIONS WITH STATIC VERSUS INTERACTIVE GRAPHICAL USER INTERFACES

\author{
A Thesis \\ Presented to \\ The Faculty of the Department of Psychology \\ San Jose State University \\ in Partial Fulfillment \\ of the Requirements for the Degree \\ Master of Arts
}

By

Naomi Ruth Jobrack-McDaniel

May 1999 
UMI Number: 1394539

Copyright 1999 by Jobrack-McDaniel, Naomi Ruth

All rights reserved.

UMI Microform 1394539

Copyright 1999, by UMI Company. All rights reserved.

This microform edition is protected against unauthorized copying under Title 17, United States Code.

\section{UMI}

300 North Zeeb Road

Ann Arbor, MI 48103 
(C) 1999

Nagomi Ruth Jobrack-McDaniel ALL RIGHTS RESERVED 
APPROVED FOR THE DEPARTMENT OF PSYCHOLOGY
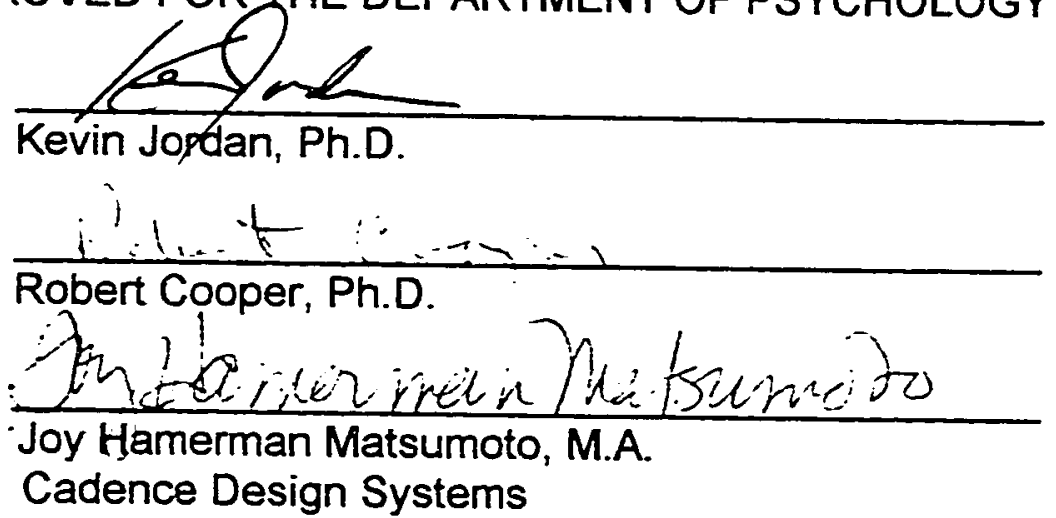

APPROVED FOR THE UNIVERSITY

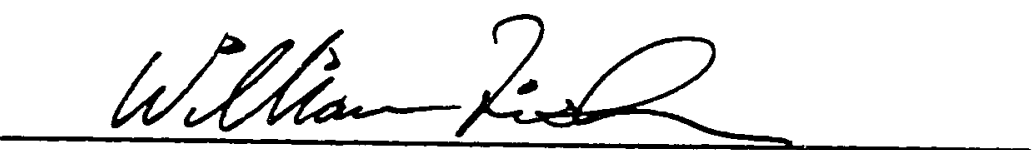


ABSTRACT

\section{REMOTE VERSUS LABORATORY USABILITY EVALUATIONS ON STATIC} VERSUS INTERACTIVE GRAPHICAL USER INTERFACES

by Naomi Ruth Jobrack-McDaniel

In a mixed design, computer generated static and interactive graphical user interfaces (GUIs) were presented to two types of end users (Software Developers, Technical Publications) for evaluation of "look and feel" and proposed functionality. The evaluations took place at remote workstations or in a usability test laboratory. The investigation sought to discover if interactive GUIs were better for presentation to evaluators than static GUIs, if remote locations were as effective as laboratory settings for this type of usability evaluation, and if relationships existed between the dependent measures (subjective, objective) and between the groups. Two analyses of variance (for subjective and objective data) revealed no effect of location. Interaction effects were found for fidelity and participant type. A Pearson's correlation revealed no relationship between the objective and subjective dependent measures. 


\section{ACKNOWLEDGEMENTS}

There are many people I would like to thank for the love and support they gave me while I was writing this thesis. First, I would like to thank my children, Rachael and Shannah, for giving up many hours of quality time during the last few months while I paid more attention the computer than to them. I want to thank my family who always believed that I could finish, even when I thought I couldn't. I am also grateful to my many friends who helped with my children and kept pushing me to continue. I am very grateful to Dr. Kevin Jordan for all of the time he spent with me and this paper, helping me to make it as perfect as possible. I would aiso like to include a special thanks to the usability staff at the software company where this study took place. Each of them contributed to this effort, helping me to lay the groundwork for the investigation. Finally, I would like to thank my committee, without whom this could not have been possible. Thanks for everything Dr. Jordan, Dr. Cooper, and Joy Matsumoto. 


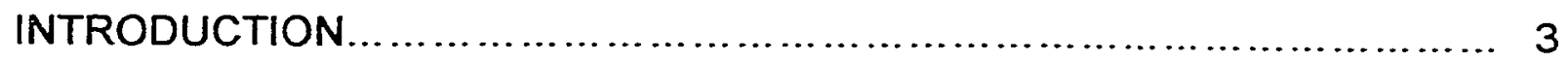

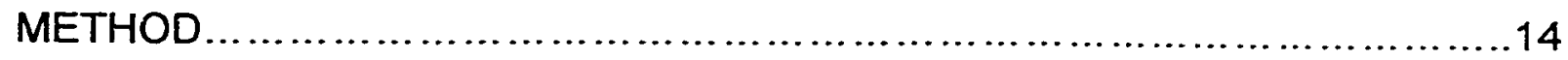

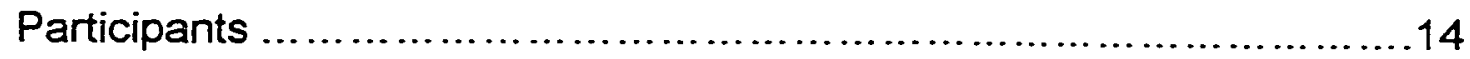

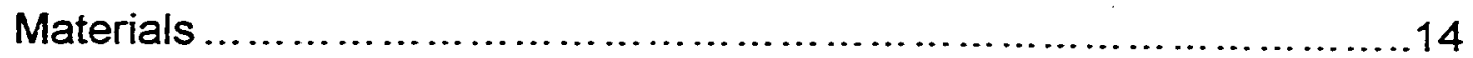

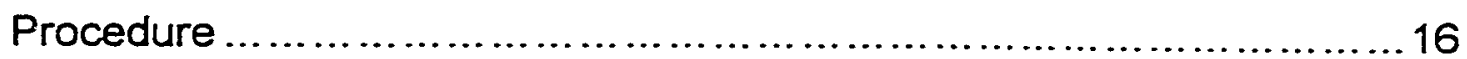

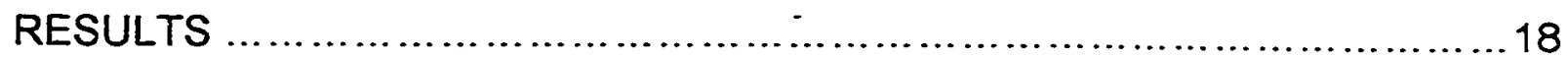

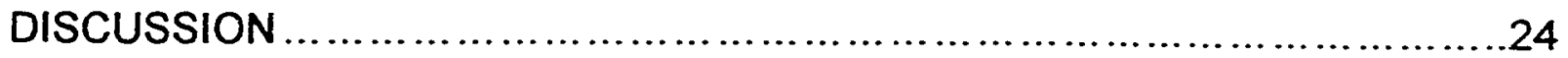

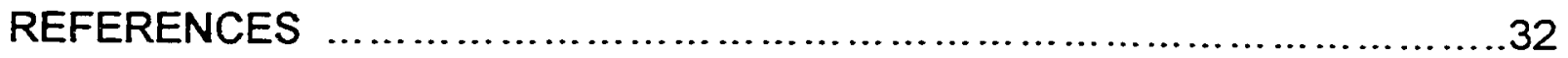

APPENDICES

Appendix A. Signed Approval Form ........................................ 35

Appendix B . Example of the Electronic Mail Invitation.....................36

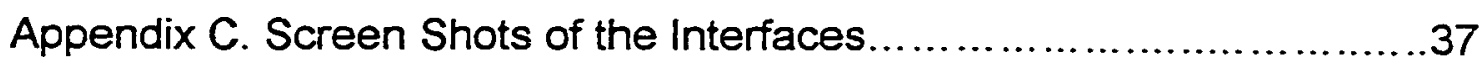

Appendix D. Interface Information Survey ...............................40 


\section{LIST OF TABLES}

TABLE

PAGE

1. Summary Table of Subjective Means 20

2. Summary Table of Objective Means .......................................... 21

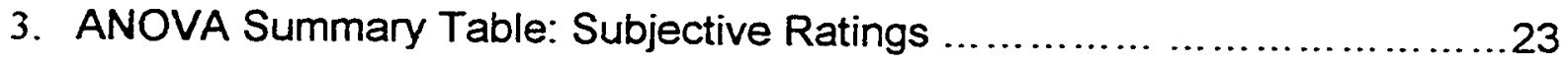

4. ANOVA Summary Table: Objective Scores .25 


\author{
Remote Versus Laboratory Usability Evaluations With \\ Static Versus Interactive Graphical User Interfaces \\ Naomi Ruth Jobrack-McDaniel \\ San Jose State University
}

Running head: LOCATION AND FIDELITY DIFFERENCES OF GUIS

\title{
Footnotes
}

Requests for reprints should be sent to Naomi Ruth Jobrack-McDaniel, Department of Psychology, San Jose State University, San Jose, California 95192. 


\begin{abstract}
In a mixed design, computer generated static and interactive graphical user interfaces (GUls) were presented to two types of end users (Software Developers, Technical Publications personnel) for evaluation of "look and feel" and proposed functionality. The evaluations took place at remote workstations or in a usability test laboratory. The investigation sought to discover if interactive GUls were better for presentation to evaluators than static GUls, if remote locations were as effective as laboratory settings for this type of usability evaluation, and if relationships existed between the dependent measures (subjective, objective) and between the groups. Two analyses of variance (for subjective and objective data) revealed no effect of location. Interaction effects were found for fidelity and participant type. A Pearson's correlation revealed no relationship between the objective and subjective dependent measures.
\end{abstract}


Remote Versus Laboratory Usability Evaluations With Static Versus Interactive Graphical User Interfaces

Computers have made their way into many facets of current work environments. People must interact with computers to do a multitude of functions throughout a workday. The cost of training and the technological aptitude of the average worker make it difficult to keep system training up with technology. Understanding the inner workings of the systems and the knowledge of command line codes is no longer necessary to use computer systems as tools to accomplish tasks.

Computer interfaces have been developed to bridge the knowledge gap between using a system and knowing how a system works. A well-designed interface allows an individual to use a system without a complete understanding of why or how the system functions. Graphical user interfaces (GUIs) were developed that use metaphors drawn from everyday experiences of the world (the most common being the "desktop", "file cabinets", and "books"), to guide the computer user intuitively through the functions and processes of the computer system (Lynch, 1994). The GUI provides a pictorial representation of the job being performed by the user, not what the system is doing, such as putting files into folders or into trash cans. This is done through the use of screen displays that orient and guide the user by presenting an environment for the user to experience that is directed, thus focusing the user on their tasks (Lynch, 1994, p24). 
The goal behind the design of the GUI is to provide an environment whereby the user needs to interact with the information presented by the graphic interface, rather than memorizing command codes. Still, systems are not automatically understood. The use of metaphor is widely accepted, yet often poorly executed in design. For metaphors to aid in GUI use, they must make sense and they must behave in the same manner as the objects or actions would in the real world (Tognazzini, 1995).

Most GUIs were created and developed for tool or task-oriented software. Each company needing such an interface for a specific tool developed their GUls in isolation. In addition, the tools and interfaces were developed on different platforms, such as Windows $\otimes$ or Unix. Thus far, only the Belcore Style Guide (1995) exists to provide guidelines for design of GUls across platforms. With the insurgence of the World Wide Web, graphical user interfaces have become a part of many people's computing experience. The graphical user interface has been introduced into almost every environment where technology meets the user. This speaks not only to the usefulness of the concept, but to the need to have GUls developed properly. GUls need to be designed to be effective, eliciting the expected response from the intended users. GUls should be easy to use. They should also provide a high level of confidence that they can be used with very few errors and with little or no training.

Software design engineers, usability engineers, and users all play very important roles in the development and testing of graphical user interfaces. 
Software design engineers create the code that lies beneath the interface, which makes it possible for the user to do their job. Usability engineers, armed with knowledge of human cognitive and motor abilities, aid the software design engineers in the design of interfaces with which humans can successfully interact. Users participate in testing human-computer interfaces throughout development, providing software and usability engineers with the information and feedback needed about the interface to advance product development (Dumas \& Redish, 1993; Tognazzini, 1995).

In everyday life, people are exposed to a multitude of interfaces, few of which have been formally evaluated and developed with the user in mind. The consequence is that many interfaces fall short of the ideal. Users become confused, make errors, and have little confidence in these interfaces. Because of this, focus has shifted from designing these interfaces as a way of presenting functionality, to designing GUls to effectively support the user, without the loss of the original functionality.

An early and cost effective method in the design of a good GUI comes in the form of a heuristic evaluation. Heuristic evaluation is an informal method of usability analysis where a number of evaluators are presented with an interface design and asked to comment on it (Nielson \& Molich, 1990). Heuristic evaluations can be done very early in the design, as well as at any step of a redesign of an interface and do not require the interface to be fully functioning. 
Originally, heuristic evaluations were designed to have evaluators who had some knowledge of usability principles but not necessarily expert knowledge. Usability experts were once seen as "expensive and hard to come by" (Nielson, 1992, p. 373). Now it is common to find usability engineers on engineering design teams. Usability engineers are becoming an integral part of those companies who want to stay competitive in the market place by developing high quality products that are engineered with the user as the focus of the design.

A first step in the evaluation phase of an interface involves mock-ups of the design. Mock-ups can be as simple as sketches on paper, or as complex as fully-functioning computer generated designs. In general, static paper prototypes are used to discover such global problems as user reactions to wording, layout, and sequencing of the interface (Shneiderman, 1998). Computer generated prototypes, built with some level of fidelity are used to expose many types of usability issues with the interface. Issues range from navigational errors, to discovering if a user responds appropriately to built in cues, to how well the interface fits the mental model of the user, to the evaluation of the length of time it takes the user to work through the interface, and to check the overall visuals of the interface (Spool, Scanlon, \& Snyder 1997).

Nielson (1990) found benefits to both paper and computer implementations for heuristic evaluations. The paper mock-up was seen as very 
cheap to implement and resulted in a substantial cut in design costs. With paper mock-ups, the user "plays" the computer. In the time since Nielson's paper, many software packages have been developed that make the creation of computer generated mock-ups quick and inexpensive. These mock-ups have the advantage of representing the actual "look and feel" of a finished product.

For a metaphor to work, a GUI must present a solid and consistent "look and feel" to the user. For the purpose of this investigation, "look and feel" is defined as consistent control behavior, terminology, layout, and style for the user interface. "Look and feel" is more than aesthetics, which Tractinsky (1997) defines as synonymous with visual beauty. The user must feel as though they are in control of the system, and that the computer will not execute functions without the user's knowledge. The Windows Interface Guidelines for Software Design (1995) serves as the basis for developing the user interfaces for the current study. The broad implementation of the Windows style across platform tools allows it to be leveraged as a solid foundation for meeting user expectations concerning the user interface.

Given the current software design capabilities, mock-ups can be generated that vary along a continuum of fidelity and at a very low cost. For the purpose of usability testing, fidelity refers to the level of functionality of the mock-up. The most pragmatic first test is based on sketches (lowest fidelity) or partially functional prototypes (Dumas \& Redish, 1993). The main purpose of low 
fidelity interface tests is to expose the user to the top-level representation of the interface and to do so early in the product development process. During this exposure, the user imagines him/herself using the tool. This method is inexpensive, yet a very effective way to discover major problems in the design before the investment of time and money into coding the functionality of the tool (Nielson, 1990).

At the very least, high-fidelity interface tests involve a partially functional interface. The use of high-fidelity prototypes in usability testing allows the user to identify problems in navigation and to assess whether the system provides appropriate feedback. High-fidelity interfaces require that some if not most of the code for the tool be written. Ideally, high-fidelity interfaces are tested later in the design phase of GUls, after much time and testing have already been invested and global problems discovered and fixed. The actual "look and feel" of the interface, if properly designed, should provide "affordances". An affordance gives the user some awareness of how to interact with the interface (using metaphors). Adding some fidelity to computer generated mock-ups can provide evaluators with a sense of how the GUI will function. Therefore, evaluators should be able to predict the functionality of the GUl by examining the mock-ups. Some of the limitations to low fidelity interface tests include the lack of feedback the system affords the evaluator, as well as it being somewhat difficult for most evaluators to "play" the computer. 
Tractinsky (1997, p. 115) found "very high correlations between perceived aesthetics of the interface and a priori perceived ease-of-use of the system." Tractinsky discusses the lack of attention to the "look and feel" of interfaces in the human computer interaction $(\mathrm{HCl})$ literature. He states that there does seem to be some practical assumption of orthogonality between the "look and feel" of a system and its perceived functionality in the current literature. His study shows the opposite, that the higher the ratings on "look and feel", the more positive the participants predicted the ease-of-use of the system. Some experts have pointed out that aesthetics have been over used. Aesthetics have even been favored over usability (Norman, 1988). "Norman (1988) ridicules the tendency of designers to neglect usability in favor of aesthetics" (Tractinsky, 1997, p. 115116). The fact is that looking good does not necessarily equate with usability. Unfortunately, Tractinsky (1997) uses the terms aesthetics (beauty) and "look and feel" (behavior) interchangeably.

Maquet (1986) and Marcus (1992) argue that aesthetics of an interface should emphasize the information processing of the user. They too, use aesthetics to describe the behavior of the GUI rather than beauty. For the purposes of the current investigation, there are differences in the definitions of "look and feel", and aesthetics. "Look and feel" is a solid and consistent layout or protocol that is used in interface design. The "look and feel" of an interface is ideally designed to take advantage of affordances, transfer of knowledge from 
familiar systems, and metaphors, and it will also aid the tool in eliciting intuitive responses from the user. Aesthetics is defined simply as the visual beauty of the display. Yet, there is some artistic design that goes into "look and feel," because interfaces should also be aesthetically pleasing. The Windows Interface Guidelines for Software Design (1995, p. 217) states, "The visual design is an important part of a software's interface. Provide a pleasant environment that clearly contributes to the user's understanding of the information presented".

In a study similar to Tractinsky (1997), Kurosu and Kashimure (1995) compared "apparent usability" with the appearance (beauty) of the interfaces of automatic teller machines. Participants rated the appearance of the interface and made predictions as to how the system would work by evaluating nonfunctional (low fidelity) mock-ups. Their findings suggested a positive relationship between aesthetics and proposed usability of the machines. Again, this study appears to use the term aesthetics to mean more than visual beauty. Since in many of the studies cited here, the term aesthetics has been used to describe the "look and feel" of an interface, to reduce confusion, the term "look and feel" will be substituted for this usage of aesthetics.

Tractinsky (1997) concluded that "look and feel" could go much farther than simply allowing users to make a judgment about ease-of-use of a system. Because the "look and feel" of a system affects the user's perception of the apparent usability, this may in turn affect the user's long-term attitudes towards, 
and their performance on, the system.

\section{Purpose of the Present Study}

The current investigation explored whether participants rated computergenerated static (low fidelity) or interactive (high fidelity) GUI mock-ups differently on "look and feel". If participants preferred some fidelity when rating "look and feel" by showing higher ratings in the interactive condition, then it may be a great cost savings to the design process to bring users into testing after some level of interactivity is coded into the GUI. Another comparison explored was the relationship between "look and feel" ratings and the objective error rates on predicted functionality. If participants give positive ratings of GUI representations, did they in fact make fewer errors with correct identification of GUI objects? Specifically, the study also assessed whether participants make more errors in selection of GUI objects or fill-in questions in static rather than interactive mock-ups, thus providing some additional comparison of the relative merits of static and interactive interfaces for GUl evaluations.

Different types of end users were conveniently available for participation in the current study, thus greatly enhancing the robustness of the investigation. Both software design engineers and technical publications personnel use the types of GUI forms that were evaluated. The two groups differed greatly in their backgrounds and expertise. Software design engineers create and code the software, and technical publications personnel supplement the software and 
GUls with printed documentation and instructions for the customers. In this investigation, both types of end users performed evaluations from a user's perspective. Many experts (Bauersfeld, 1994; Dumas \& Redish, 1993; Tognazzini, 1997) have speculated on the difference between designers and end users. Assumptions have been made, yet not experimentally tested, that these two groups process information differently based on different educational and experiential exposure. For the purpose of this investigation, the participants all performed the same tasks, evaluating the interfaces. Thus, interest focused on the differences occurring based on the unique knowledge possessed by the two participant groups.

The current study was similar in design to that of Tractinsky (1997). Using computer monitors, he presented interfaces to participants. Using the keyboard, the participants made subjective ratings for ease-of-use (predicted functionality) and for "look and feel". In three experiments, Tractinsky found positive correlations between these two variables. Smilowitz, Darnell, and Benson (1994) tested participants in two locations (a usability lab and remote workstations) to discover if beta testing at remote locations would provide the same type and amount of usability information as conventional usability laboratory testing. Smilowitz et al. (1994) found that the lab tests were as effective as the remote tests for discovering a number of usability problems. However, they found the remote test method to be more cost effective, while the 
lab tests uncovered a larger portion of more serious usability problems.

The current study explored the preferences and responses of software design engineers and technical publication personnel to two GUI mock-ups; one mock-up was static and the other was interactive. In a simple heuristic evaluation, static and interactive interfaces were compared by the two groups to discover if fidelity of the GUI affects the ratings of "look and feel" and the ability to select the correct GUI objects from questions on predicted functionality. Based on the findings of Kurosu and Kashimure (1995) and Tractinsky (1997), a negative correlation was expected between participant's ratings of "look and feel" and number of errors they made in selection of GUI objects. The two groups completed these evaluations in two settings, either in a test lab or at personal computing workstations.

In both locations, the evaluations followed the same basic format. The users read an electronic mail invitation to participate in the study then followed an embedded link to the study. They then completed and submitted the evaluation. In the lab setting, participants were run through the evaluation in a traditional manner. Participants were brought into the lab and seated at a computer workstation. They were instructed that all the information necessary to complete the task was available to them through the computer. They were also told that they would be left alone in the lab and observed from behind a one-way mirror. The researcher did not aid or interfere with the participants during the 
session. In the remote setting, participants performed the same evaluations in their own work environments.

\section{Method}

\section{Participants}

Twelve software design engineers and 12 technical publications personnel were sent letters of introduction through the electronic mail system at the software company where they worked (see Appendix B). A hyper-link was embedded in the letter that directed the participants to the stimuli. By following the link and completing the questionnaire, the participants gave their consent to participate in the study. Another 24 participants, 12 designers and 12 technical publications personnel, were solicited and brought into the usability lab at the software company. They were run through the evaluation in the same manner as those at the remote personal computing workstations.

\section{Materials}

Two graphical user interfaces were designed by Usability Engineering at the software company. The first form was a product change request form (PCR). This form would be used by employees of the software company to let project teams know of problems that exist with a product. The second form used in testing was an experimental timecard that was intended for all employees (see Appendix C). Each of these interfaces had two levels of fidelity, static and interactive. The questionnaires were presented within an internet browser 
window. The participants were instructed to bring up another window, along side of first window, to view the two interfaces. This was done by clicking on a button embedded in the instructions. There were two WEB pages designed this way, which enabled the participants to interact with the stimuli and view the survey simultaneously. Each page contained two buttons that brought up the two GUls, either static or interactive. The survey contained an overview of the purpose of each GUI, fill-in questions ( 20 for the first GUI and 12 for the second) concerned with predicted functionality for each interface and five subjective questions concerned with "look and feel". The survey also included a text box at the bottom of the page for participant feedback. The mock-ups were designed according to the usability guidelines provided in the Belcore Style Guide (1995). Participants used computers, with keyboards and monitors, either at their remote workstations or in the usability lab to interact with the stimuli. Statements for the subjective ratings, and questions for the objective questions and fill-in questions, were developed and selected based on current guidelines used in heuristic evaluations at the software company where the study took place. A large list of statements and questions was generated and then the items were presented to a panel of usability engineers with expertise in GUI development. This panel selected five statements for the subjective portion of the evaluation on "look and feel" and sixteen questions for the fill-in section on predicted functionality, ten for the PCR and six for the time card. Each fill-in question was followed by an 
objective question that asked the participant to choose the method they would select for specifying their answer if they were actually filling out the GUI. Each participant was therefore required to fill-in their responses as to what they would enter on the GUI form, and then select one of seven options that determined how they would put their answer into the GUI form (see the survey in Appendix D). Additionally, two scenarios were developed by the usability group, which created the settings for the objective portion of the survey. Participant's subjective answers were scored on a scale from one to five, representing their level of agreement with the statement. One represented their lowest level of agreement, where as five represented their highest. The objective ratings were scored on a zero to two scale. For the fill-in half of each question, participants were given a zero if they filled-in an incorrect response, a one if their response was a possible answer but not correct for the current scenario, and a two if they filled-in the correct answer. The objective half of each question was scored with the same range of zero to two. Participants were given a zero if they chose the wrong method for entering the data or chose more than three methods. They were given a one if they chose two methods, one of which was correct and the other plausible. Participants were given a two for a single correct response.

\section{Procedure}

The participants were tested in a mixed-design. Level of fidelity of the GUls was the within subjects variable. Each participant was tested in both 
conditions, static and interactive, in random order, one week apart. In both conditions, either on their remote workstations or on the usability test laboratory computers, participants were presented with two computer generated GUIs, and a general description of the purpose of each interface. The computers were connected to the company's internal web, thus allowing access to the web sites through the use of a web browser. The participants were instructed that they were doing a heuristic evaluation of each interface. The evaluation consisted of having the participants read through scenarios and answer fill-in and objective questions that related to the proposed functionality of the GUI. These questions required participants to evaluate the GUls and figure out what was to be entered or selected on the interface to complete the task. They were required to choose the GUI objects that they felt best satisfied the questions and answer the question relating to the functionality of the GUI. Participants filled-in their responses in provided text boxes and then checked a box to note how they would have made their choice on the GUI. Participants were also required to rate five statements concerning the "look and feel" of each interface on a five-point Likert-type scale with five representing the highest level of agreement and one representing the lowest level of agreement. Participants were able to click on one of a set of labeled radio buttons that best represented their level of agreement with the statements. 


\section{Results}

In a mixed design, with fidelity as the within subjects variable, two types of participants (24 software design engineers and 24 technical publications personnel) evaluated the "look and feel" and proposed functionality of computer generated graphical user interfaces (GUIs). The evaluations took place in two locations (remote sites and in a usability test laboratory). The investigation sought to answer the following three questions: Are remote locations as effective as laboratory settings for conducting usability evaluations of GUls? When presenting computer generated GUls to evaluators, are preference ratings higher for interactive or static GUIs? Are there differences between software designers and technical publications personnel performances in GUI evaluations?

Before performing the statistical analysis, missing values were replaced with the overall mean scores for each participant. The number of missing values for the laboratory group was 46 and for the remote group was 29. Based on laboratory observation, missing values occurred either when participants failed to transfer their answers from the interface to the survey or they scrolled past the questions and skipped them. No observations could be made in the remote condition; therefore there can be no definitive explanation for those missing values. Composite scores were then created to combine the responses for the two GUls in both conditions. To combine the scores from the objective 
responses and create the composite scores, the mean percent correct for both GUls were averaged for each participant. For the PCR GUl a total of forty points were possible and for timecard GUI (FASB) a total of 24 points were possible. The mean percent correct was calculated for the individual GUIs before the two were averaged together. To combine the ratings from the subjective data, the mean ratings were added then averaged for each participant. The mean scores and standard errors for all conditions are presented in Table 1 and Table 2. Analysis

To examine the three questions above, two analyses of variance (ANOVAs) were conducted. The first analysis was a 2 (location) $\times 2$ (participant type) $\times 2$ (level of fidelity) mixed analysis of variance on the subjective ratings. The second analysis was a 2 (location) $\times 2$ (participant type) $\times 2$ (level of fidelity) mixed analysis of variance on the objective ratings. For both analyses, level of fidelity was the within subjects variable. A Pearson's correlation was also conducted to discover the relationship between the two dependent measures and revealed no significant relationship, $\underline{r}(48)=.25, \underline{p}=.087$. Both groups (software engineers, technical publications personnel) performed about the same in the two locations. More important were the larger differences noted between the ratings and the objective responses made for the two levels of fidelity. 


\section{Table 1. Subjective Data}

\section{Summary Table of Subjective Means}

\begin{tabular}{ccccc} 
Software & Developer & & \\
\hline Subjective & Static & Standard Error & Interactive & Standard Error \\
\hline Lab & 3.50 & .19 & 3.42 & .13 \\
Remote & 3.44 & .14 & 3.31 & .20 \\
\hline Mean & 3.47 & & 3.36
\end{tabular}

Technical Publications

\begin{tabular}{ccccc}
\hline Subjective & Static & Standard Error & Interactive & Standard Error \\
\hline Lab & 3.64 & .15 & 3.87 & .13 \\
Remote & 3.40 & .13 & 3.61 & .10 \\
\hline Mean & 3.52 & & 3.74 &
\end{tabular}




\section{Table 2. Objective Data}

Summary Table of Objective Means

\begin{tabular}{ccccc} 
Software & Developer \\
& \multicolumn{5}{l}{} \\
\hline Objective & Static & Standard Error & Interactive & Standard Error \\
\hline Lab & .73 & .02 & .77 & .03 \\
Remote & .78 & .04 & .78 & .05 \\
\hline Mean & .755 & & .755 &
\end{tabular}

Technical Publications

\begin{tabular}{ccccc}
\hline Objective & Static & Standard Error & Interactive & Standard Error \\
Lab & .81 & .02 & .89 & .02 \\
Remote & .78 & .02 & .87 & .03 \\
\hline Mean & .795 & & .880 &
\end{tabular}




\section{Subjective Data}

In all conditions, software developers rated the GUIs lower than the technical publications personnel. The first ANOVA, on the subjective data, evaluated the effects of location, participant type, and fidelity. The results showed no effect of location. An interaction occurred between fidelity and participant type, $E(1,44)=4.68, \underline{p}=.036$. A separate one-way analysis of the subjective data for the interactive GUI condition showed that the technical publications personnel rated the interactive GUIs significantly higher than did the software developers, $E(1,46)=6.86, \underline{p}=.012 . M=3.74$, (SE .08) $[M=3.36$, (SE $=.12$ ) respectively]. The two groups had roughly equivalent ratings for the static interface (see Table 3 for the subjective ANOVA summary).

\section{Objective Data}

Software developers scored lower on the objective portion of the survey than did the technical publications personal in all conditions. The second ANOVA, on the objective data, examined the effects of location, participant type, and fidelity. The results showed no effect of location. A main effect of participant type $\mathrm{E}(1,44)=6.98, \underline{\mathrm{g}}=.001$, supported the prediction that a difference in performance between the two groups may exist. Technical publications personnel were more successful in their responses on the objective portion of the survey than were the software developers $\underline{M}=.84$, $(S E=.01)$ and $\underline{M}=.77$ $(S E=.02)$ respectively]. Both participant types were significantly more 
Table 3.

ANOVA Summary Table: Subjective Ratings

\begin{tabular}{|c|c|c|c|c|c|}
\hline SOURCE & SS & $d f$ & MS & $F$ & $p$ \\
\hline mean & 1192.2961 & 1 & 1192.2961 & 3021.184 & 0.000 \\
\hline Loc/Type & 17.3644 & 44 & 0.3946 & & \\
\hline Location & 0.6633 & 1 & 0.6633 & 1.681 & 0.202 \\
\hline Loc/Type & 17.3644 & 44 & 0.3946 & & \\
\hline Type & 1.1094 & 1 & 1.1094 & 2.811 & 0.101 \\
\hline Loc/Type & 17.3644 & 44 & 0.3946 & & \\
\hline Loc/Type & 0.1650 & 1 & 0.1650 & 0.418 & 0.521 \\
\hline Loc/Type & 17.3644 & 44 & 0.3946 & & \\
\hline Fidelity & 0.0771 & 1 & 0.0771 & 0.552 & 0.462 \\
\hline Fidelity/ Loc/Type & 6.1456 & 44 & 0.1397 & & \\
\hline Loc/Fidelity & 0.0063 & 1 & 0.0063 & 0.045 & 0.832 \\
\hline Fidelity/ Loc/Type & 6.1456 & 44 & 0.1397 & & \\
\hline Type/Fidelity & 0.6534 & 1 & 0.6534 & 4.678 & $0.036^{\star}$ \\
\hline Fidelity/ LocTType & 6.1456 & 44 & 0.1397 & & \\
\hline Loc/fid/Type & 0.0018 & 1 & 0.0018 & 0.013 & 0.909 \\
\hline Fidelity/ Loc/Type & 6.1456 & 44 & 0.139 & & \\
\hline
\end{tabular}


successful in their responses in the interactive condition as well, $E(1,44)=$ $12.83, \underline{p}=.001$. The means for static and interactive responses were, $\underline{M}=.77$ $(\mathrm{SE}=.018)$ and $\underline{M}=.83(\mathrm{SE}=.013)$ respectively. Finally, the analysis revealed a significant interaction of participant type and fidelity $\underline{E}(1,44)=4.265, \underline{p}=.045$. A separate one-way analysis of variance of the objective data for the interactive GUl condition showed that the technical publications personnel were more successful in their responses on the objective portion of the survey than were the software developers on the interactive interface. $E(1,46)=9.19,2=.004$. The means for the technical publications personnel and software developers for the interactive level of fidelity were $\underline{M}=.88(S E=.02)$ and $\underline{M}=.78(S E=.03)$ respectively. No effect was noted with the static GUI scores [see Table 4 for the objective ANOVA summary].

\section{Discussion}

In a mixed design, with fidelity as the within subjects variable, two types of participants (24 software design engineers and 24 technical publications personnel) evaluated the "look and feel" and proposed functionality of computer generated graphical user interfaces (GUls). The evaluations took place in two locations (remote sites and in a usability test laboratory).

\section{Location Effectiveness}

The first question this investigation sought to answer was whether remote locations are as effective as a laboratory setting for conducting usability 
Table 4:

ANOVA Summary Table: Objective Scores

\begin{tabular}{|c|c|c|c|c|c|}
\hline SOURCE & SS & $d f$ & MS & $F$ & $\underline{p}$ \\
\hline$\overline{\text { Mean }}$ & 61.5360 & 1 & 61.5360 & 3694.303 & 0.000 \\
\hline Loc/Type & 0.7329 & 44 & 0.0167 & & \\
\hline Location & 0.0001 & 1 & 0.0001 & 0.009 & 0.925 \\
\hline LocTType & 0.7329 & 44 & 0.0167 & & \\
\hline Type & 0.1162 & 1 & 0.1162 & 6.976 & $0.011^{\star}$ \\
\hline Loc/Type & 0.7329 & 44 & 0.0167 & & \\
\hline Loc/Type & 0.0150 & 1 & 0.0150 & 0.901 & 0.348 \\
\hline Loc/Type & 0.7329 & 44 & 0.0167 & & \\
\hline Fidelity & 0.0782 & 1 & 0.0782 & 12.826 & 0.001 \\
\hline Fidelity/LocType & 0.2683 & 44 & 0.0061 & & \\
\hline Location/Fidelity & 0.0024 & 1 & 0.0024 & 0.394 & 0.534 \\
\hline Fidelity/ Loc/Type & 0.2683 & 44 & 0.0061 & & \\
\hline Type/Fidelity & 0.0260 & 1 & 0.0260 & 4.265 & $0.045^{\star}$ \\
\hline Fidelity/ Loc/Type & 0.2683 & 44 & 0.0061 & & \\
\hline Loc/Type/Fidelity & 0.0006 & 1 & 0.0006 & 0.098 & 0.755 \\
\hline Fidelity/ LocTType & 0.2683 & 44 & 0.0061 & & \\
\hline
\end{tabular}


evaluations of GUls. The results of this study supported the work done by Smilowitz, et al. (1994) who tested in separate locations searching for costeffective ways to conduct some kinds of usability analysis on software. The current investigation found that participants returned the same response patterns from both the laboratory setting and the remote settings. There were no main effects or interactions involving the location variable for either the subjective or objective data.

One might conclude that conducting this type of evaluation does not have to be done in a laboratory because no additional information is gained, and they could save the costs associated with a laboratory. Still, without the ability to observe evaluators working through a product there is no way to discover where all of the problems exist. During the course of this investigation, much information was gleaned through observation and debriefing interviews of the laboratory participants.

While observing participants work through the scenario and survey, the researcher could take note of how the participant worked through the evaluation. It was obvious why some questions were left unanswered. For example, the researcher noticed that a few users had to scroll many times through the survey to refresh their memories of the task scenario. They would then scroll back to the wrong position in the survey and leave some questions unanswered. In post evaluation interviews, participants explained in detail why they made the 
selections and choices to each question. Here it was discovered where they were confused by terminology and how they would make changes to the interface to make it more clear and understandable. No such input was gathered from the remote subjects. If one would like a quick and inexpensive, yet not complete and or detailed, opinion of an interface, this investigation showed that it is feasible to gain this information remotely. Still, for the reasons mentioned above, it is not recommended to forgo structured usability testing and loose the valuable information that can only be gathered through trained observation. Fidelity Preference and Performance

The second question this investigation sought to answer was whether or not participants rated static or interactive computer-generated GUls higher in preference and if a difference in response patterns could be found between the participant types. Results showed that although not significant, in all conditions technical publications personnel not only rated the interfaces higher on "look and feel" qualities, they were also more successful in answering the fill-in and objective questions. Although the results showed that there was no statistical difference in ratings between technical publication personnel and software developers for the static interfaces, the interaction highlights the differences that did occur between these two participant types. Thus, given some level of interactivity a difference between how each participant type reacted to the interface began to emerge. These findings support the assumptions made by 
many researchers and experts (Bauersfeld, 1994; Dumas \& Redish, 1993; and Tognazzini, 1995) who have claimed that there is a difference in the way information is processed between engineers who design products and others, end users, who use these products. Although both participant types were acting as end users in this study, technical publications personnel would be considered as a more typical end user for these types of interfaces.

Some fascinating results emerged from this investigation. The fact that the two groups of participants did not differ in their response patterns for the static GUI actually revealed some interesting possibilities. Based on observations made of the 24 participants who took the survey in the testing laboratory, it was noticed that in the static conditions both groups were frustrated with the forms. They made comments that dealt more with poor labeling. They could not figure out what some of the fields might contain. Of those who were frustrated, most did a best guess on the answers. But, when participants went through the interactive GUls, there was a clear difference between the participant types. The technical publications personnel tended to work through the interfaces like they would if they needed to describe its contents and use. They made very few comments about what the form should do, commenting only on what it appeared to do. The software developers on the other hand, given the opportunity to interact with the interface, tended to redesign the GUls. They made choices for how an item should be selected not by what the form offered, 
but by how they would design it to work. In other words, the technical publications personnel based their answers on what they saw and the software developers based their answers on how they felt it could be improved. These findings fully support the notion of educational and experiential differences between the two groups.

Another interesting finding was that software developers also rated the interactive GUls lower than the technical publications personnel. Debriefings as well as observations of laboratory participants revealed that when the software developers could interact with the GUls they found themselves dissatisfied with the selection options provided by the GUI, thus offering alternative design ideas and lower ratings on "look and feel". Since no observations or debriefing took place for the remote participants, no explanations for their response patterns can be offered.

\section{Relationship Between Measures}

A third question of interest in this investigation was to discover the relationships between the dependent measures (subjective ratings, objective scores) and between the participant types. A general trend appeared that showed an increase in "look and feel" ratings along with an increase in successful responses to objective questions, except in subjective ratings for the remote participants. The trend was not significant, a Pearson's correlation revealed no relationship between these two measures. 


\section{Conclusions}

This investigation was an effort to gain a better understanding of three main questions. The first was to discover at which point in the design process is it best to bring in end users for evaluation of GUls. An interesting finding occurred. The response patterns for the two types of evaluators were the same for the static GUls and different for the interactive. The evidence showed that if presented with static GUls, evaluators of any appropriate background (targeted end users) will work through the evaluations in a similar way. Highlighted will be the more global problems, such as ambiguous labels. Because software developers were more apt to make design recommendations rather than just accept the interface as it was, it is recommended that software developers be brought in early in the design phase, before all of the interactivity is coded for the interface. Non- developers should not be brought in for evaluations until the GUI is coded enough so that they can interact with the functionality. It is important that the end user be able see how the interface will actually work. Even though the technical publications personnel out performed the software developers in both the static and the interactive conditions, the most success for the technical publications personnel was seen in the interactive condition. In support of Smilowitz et al. (1994), this investigation showed that it could be cost effective to send evaluations out to targeted end users, but without observing participants in the laboratory setting, it is difficult to discover and assess the 
evaluators interactions with the GUIs. A greater cost would be the loss of the valuable information gained by observation.

This investigation showed a difference in how participant types interacted and rated interactive GUls. The investigation did not reveal a relationship between the dependent measures. The investigator believes there is value in the further exploration of the differences between how developers of interfaces and those of end users interact with interfaces. Knowing these differences can aid in more productive methods of evaluation. Usability specialists can utilize these differences throughout the iterative process of developing the interfaces as each group has valuable input at different stages of GUI development. For future investigations into this area of interest, it is recommended that actual usability tests and walkthroughs be conducted rather than simple evaluations. 


\section{Reference}

Belcore Style Guide. Design guide for multiplatform GUls (1995). Piscataway, NJ: Belcore.

Bauersfeld, P. (1994). Software by design: Creating people centered software. New York: M\&T Books.

Dumas, J.S. \& Redish, J.C. (1993). A practical guide to usability testing. Norwood, N.J.: Ablex Publishing Co.

Kurosu, M. \& Kashimure, K. (1995). Apparent usability vs. inherent usability, Computer Human Interaction '95 Conference Companion. (Denver, Co, May 7-11), 292-293.

Lynch, P. J. (1994). Visual design for the user interface: Part 1: Design fundamentals. Journal of Biocommunications, 21(1): 22-30.

Maquet, J. (1986). The aesthetic experience. New Haven, CTYale: University Press.

Marcus A. (1992). Graphic design for electronic documents and user interfaces. New York: ACM Press.

Morris, M.G. \& Dillion A.P. (1996). The importance of usability in the establishment of organizational software standard for end-user computing. International Journal of Human Computer Studies, v45, n2 243-256.

Nielson, J. (1989). Usability engineering at a discount. In G. Salvendy, \& M.J. Smith, (Eds.), Designing and Using Human-Computer Interfaces and 
Knowledge Based Systems, (394-401). Amsterdam: Elsevier Science Publishers.

Nielson, J. (1992). Finding usability problems through heuristic evaluation. Proc. ACM CHI'92 (Monterey, CA, 3-7 May), 373-380.

Nielson, J. \& Molich, R. (1990). Heuristic evaluation of user interfaces. Proceeds of the Association for Computing Machinery Computer Human Interaction 1990 (Seattle, WA, 1-5 April), 249-256.

Norman, D. (1988). The design of everyday things, New York: Basic Books.

Shneiderman, B. (1998). Designing the User Interface: Strategies for Effective Human-Computer Interaction. Reading, MA: Addison Wesley Longman, Inc.

Smilowitz, E.D., Darnell, M.J., \& Benson, A.E. (1994). Are we overlooking some usability testing methods? A comparison of lab, beta, and forum tests. Behavior \& Information Technologv, v13, (12), 183-190.

Spool, J. M., Scanlon, R. \& Snyder, C. (1997). Product usability: Survival techniques. Proceeds of the Association for Computing Machinery Computer Human Interaction 1997 (Atlanta, GA. 22-27 March), 154-155.

Tognazzini, B. (1995). Tog on Interface New York, NY: Addison Wesley Longman, Inc. 
Tractinsky, N. (1997). Aesthetics and apparent usability: empirically assessing cultural and methodological issues. Proceeds of the Association for Computing Machinery Computer Human Interaction 1997 (Atlanta, GA. 22-27 March), 115-122.

Windows Interface Guidelines for Software Development. (1995).

Redmond, WA: Microsoft Press. 


\section{Appendix A}

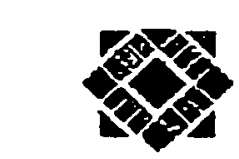

\section{San José State UNIVERSITY}

ornce of the henente

Vloo Propldent

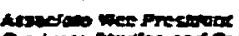

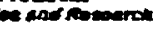
Cre reevclos $5=000$

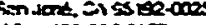
Dick

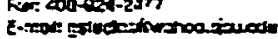

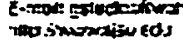

TD:

Nhami McDanic

693 Cosidey Dr.

San Jose, CA 95117

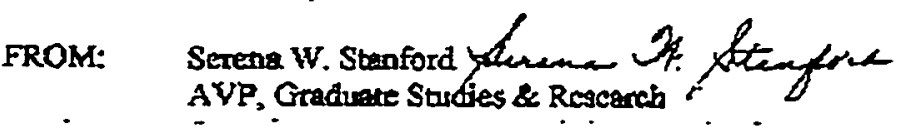

DATE: Apal 16, 1998

The Haman Subjects-Institutional Review Baud has approved your rexpest to ase human subjects in the stady eutitied:

"Remote Versns Labomory Usability Evaluations an Static Yersus Internctive Graphical User Interfices"

This approval is contingent upon the sonbjects purticipating in your reseanch project being appropriatety protected from isik This includes the protection of the anooymity of the subjects' idectity when they participate in your resureh project, and with reyend to any and al dath that may be collocted from the subjects. The Board's epproval ineludes contimed moniforing of your research by the Board to assore that the subjects are being adequately and properly protected from such rists. If at any time a subject becomes injured or complains of injury, you must notify Serea Stanford, Ph.D., indenediately. Injury incledes but is not limited to bodily han psyctiologioal traim and release of porentially dameging personal information.

Plense also be advised that all subjeots need to be finlly informed and aware the theit particination in your researcin project is voluntary, and that he or she moy withdraw from the project at any time. Further, a subjects participation, refiusal to participate, or withdrawal will not affect any services the subjoct is recciving or will rective at the institution in which the resestath is being conducted.

If you have any questions, please contact tore at (408) 924-2480. 


\section{Appendix B}

Sample of Electronic mail invitation to participate:

You have been chosen to be part of a research study being conducted here. A graduate student from San Jose State University, who is also an intern in the Usability Engineering group, is conducting the study. You have been selected because you meet special qualifications that enable you to be viewed as an expert evaluator for the purposes of this study.

The study involves two quick heuristic evaluations of graphical user interfaces. It is estimated that the evaluations will take approximately 20 minutes each and will be issued to you 7 days apart. Your participation in this study is completely voluntary, and all data collected will be kept strictly confidential. If at any point in the future, the study is submitted for publication, your name will in no way be connected to the publication. Any questions you may have can be directed to Joy Matsumoto at Cadence extension 7526 or to Kevin Jordan, Ph.D. at San Jose State University (408) 924-5626. For questions or complaints about research subjects rights contact Serena Stanford Ph.D. AVP Graduate Studies and Research at San Jose State University (408) 924-2480.

To accept the invitation and be a contributor to this study, click on the link below. Thank you very much, in advance for your participation. 


\section{Appendix C}

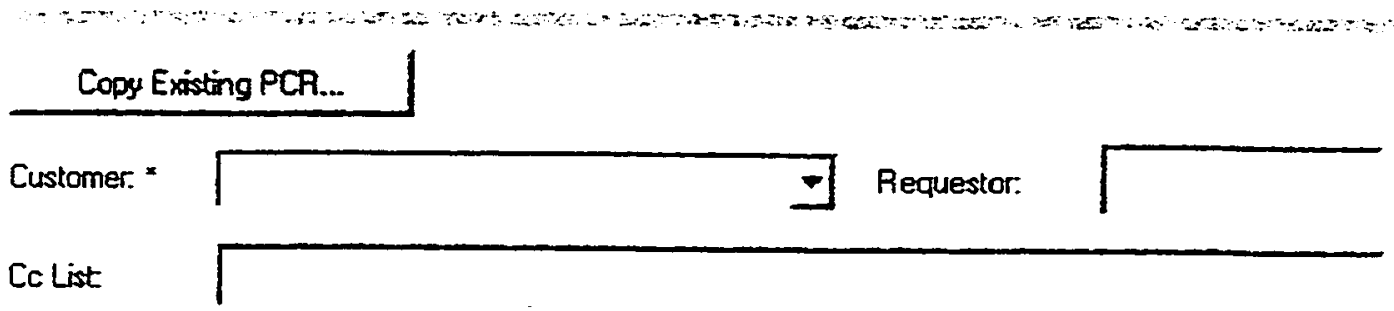

\section{Product and Environment}

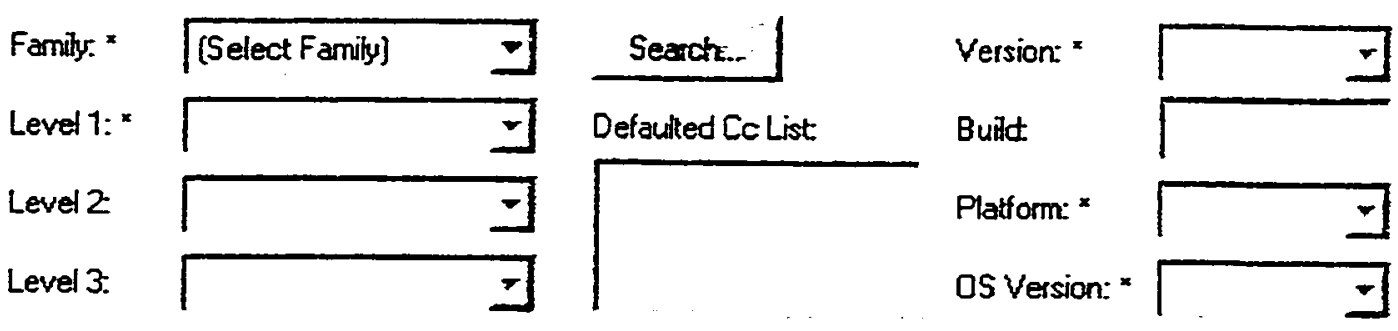

\section{Problem Report}

Type: $\sigma_{\text {8ug }} \Gamma_{\text {Enhancement }} \sigma_{\text {Question }}$

Problem Area: ${ }^{*} \quad \Gamma$ Software $\quad \Gamma$ Documentation $\Gamma$ Test

Requestor Prionity. ${ }^{*}$ PO-Severe $\quad-$ Rieference ID:

Title: *

Description: *

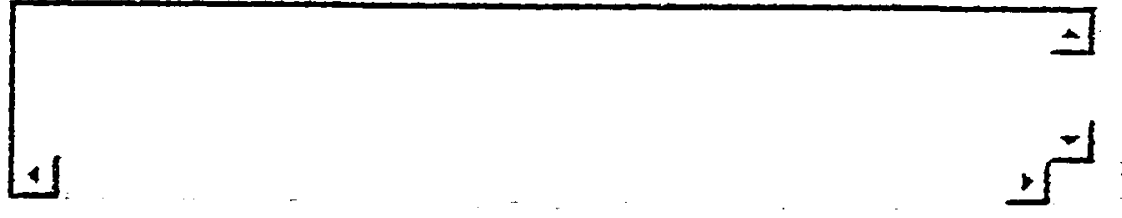

Corporate Keywords: $\Gamma$ Usability $\Gamma$ Migration $\Gamma$ flow $\Gamma$ vSI

Local Keywords:

$\Gamma$ Test Case Path:

Sumit Clear I Help

- =

PCR Add form in static representation 
Cops Existing PCR...

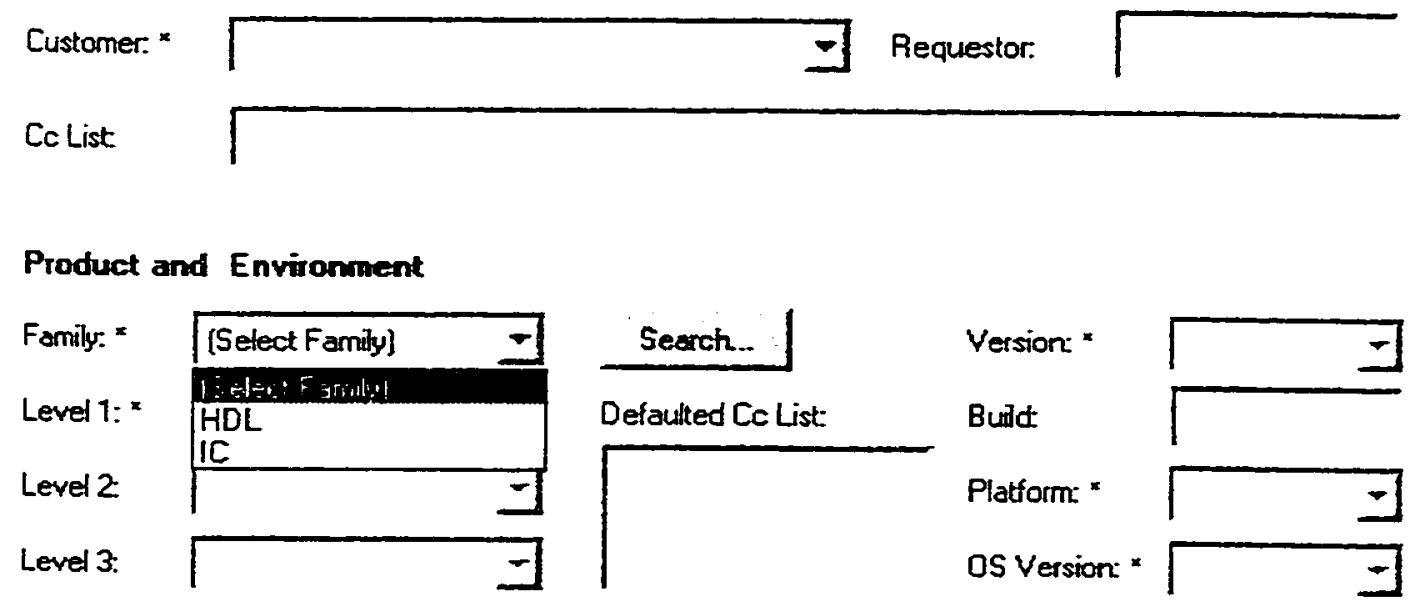

\section{Problem Report}

Type: ${ }^{*}$ Bug $r$ Enhancement $r$ Question

Problem Area: * $\Gamma$ Software $\Gamma$ Documentation $\Gamma$ Test

Requestor Priority. $=$

Titte:

Description: *
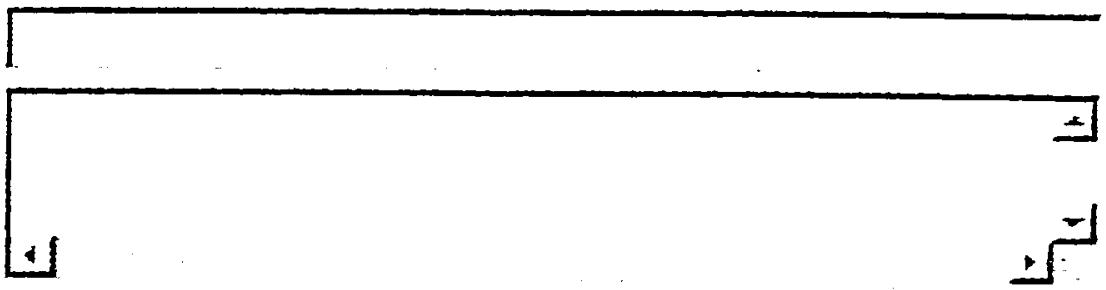

Corporate Keywords: $\Gamma$ Usebility $\Gamma$ Migration $\Gamma$ Flow $\Gamma$ vsl

Local Keywords:

$\Gamma$ Test Case Path:

Subin $\mid$ Clear | Hep

$\because \mathrm{P}$ -

PCR Add form in interactive representation 


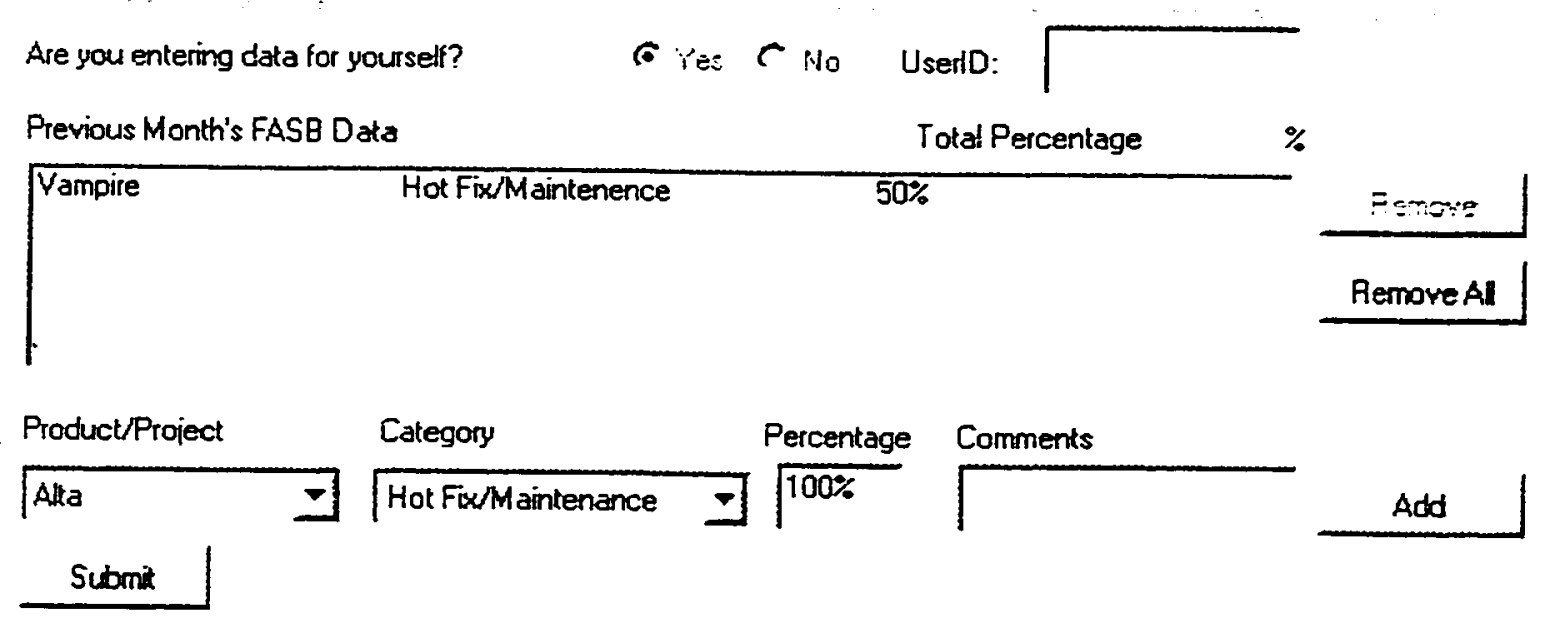

FASB form in static representation

Are you entering data for yourself?

6 Yes $C \mathrm{NI}$ UserlD:

Previous Month's FASB Data

Total Percentage

$\%$

\begin{tabular}{|lll|}
\hline Vampire Hot Fix/Maintenence & Rernovis \\
& & Rernove Al / \\
\hline
\end{tabular}

Product/Project

\section{Category}

Percentage

Comments

\begin{tabular}{|c|c|}
\hline Alta & Hot Fox/M aintenance \\
\hline Submit & $\begin{array}{l}\text { Development } \\
4.421 \\
\text { Cascade } \\
\text { Other (provide comments) }\end{array}$ \\
\hline
\end{tabular}

FASB form in interactive representation 


\section{Appendix D}

\section{Interface Information Survey}

Below you will find two buttons that link to virtual paper prototype interfaces. These forms have been developed to support this research project and resemble forms being evaluated for adding PCRs and for entering FASB data. As possible end users of these forms, your input is a valuable resource to the development of these designs. Your task is to explore the forms, follow a task scenario and fill-in answers to a few question as well as make some ratings about how you feel about the forms. Some of the forms have been partially coded so that you can interact with them, but for the most part you will be required to mentally walk through the steps of the scenarios. Your answers must be filled in on the survey, not on the forms you are evaluating. You may need to move the windows around to view both the survey and the forms. Feel free to use the mouse and keyboard in your explorations. When you have completed your evaluations, please click the submit button at the bottom of the page.

Thank you very much for your participation.

$$
\frac{\text { View PCR Add Form }}{\text { (May take a while to load) }}
$$

In the following scenario, you are required to file a PCR. The PCR form is a mock-up so you are required to mentally walk through the steps that you would take to complete the tasks. You are an AE supporting-Toshiba. You have just returned from a customer visit and want to file a PCR. A Toshiba engineer was showing you a design in the 5.1 version of Silicon Ensemble. The software was running on a SUN4/5.5 workstation. She had a question about the "Filter" field on the Open Design Form and you suggested that she click the HELP button on the form. To your embarrassment, the form help does not mention the "Filter" field at all!

Please explain how you would fill in the information to file the PCR. You know that Silicon Ensemble is listed in the PCR database as SIL_ENS.

The asterisks are used to show required data. These fields must be filled in to submit the PCR. Using the PCR form as a guide please mark, on the 
survey, the steps you would take to specify the following information for the PCR.

Please read each question and fill in a short answer to each one and then check the method you would use to enter the data.

1a. What would you enter on the PCR form for the field labeled "Customer Name"?

1b. How would you specify the Customer Name on the PCR form?

Il would type it in.

$\exists$ I would select it from a drop-down list.

I would choose a radio button.

$\exists$ I would check a box.

$\checkmark$ The software filled the field for me.

$\exists$ Other:

$\exists$ I don't know how I would specify the data with this form.

2a. What would you enter on the PCR form for the field labeled "Family"?

2b. How would you specify the "Family"on the PCR form?

$\sqsupset$ I would type it in.

$\exists$ I would select it from a drop-down list.

$\exists$ I would choose a radio button.

\rfloor would check a box.

$\exists$ The software filled the field for me.

$\sqsupset$ Other.

\lrcorner don't know how I would specify the data with this form.

3a. What would you enter on the PCR form for the field labeled "Level"?

3b. How would you specify the "Level"on the PCR form? 
Jl would type it in.

II would select it from a drop-down list.

\lrcorner 1 would choose a radio button.

II would check a box.

$\exists$ The software filled the field for me.

Jother:

$\mathcal{J}$ l don't know how I would specify the data with this form.

4a. What would you enter on the PCR form for the field labeled 'Version"?

4b. How would you specify the "Version"on the PCR form?

11 would type it in.

$J$ would select it from a drop-down list.

$\exists$ I would choose a radio button.

II would check a box.

$\exists$ The software filled the field for me.

Jother:

I don't know how I would specify the data with this form.

5a. What would you enter on the PCR form for the field labeled "Platform"?

5b. How would you specify the "Platform"on the PCR form?

$\exists$ I would type it in.

I would select it from a drop-down list.

I would choose a radio button.

II would check a box.

The software filled the field for me.

Jother:

Il don't know how I would specify the data with this form.

6a. What would you enter on the PCR form for the field labeled "OS Version"?

6b. How would you specify the "OS Version"on the PCR form? 
JI would type it in.

JI would select it from a drop-down list.

$\downarrow$ would choose a radio button.

$\exists$ I would check a box.

$\exists$ The software filled the field for me.

$D$ Other:

II don't know how I would specify the data with this form.

7a. What would you enter on the PCR form for the field labeled "Type"? 7b. How would you specify the Type

7b. How would you specify the "Type"on the PCR form?

11 would type it in.

II would select it from a drop-down list.

$\exists$ I would choose a radio button.

$\exists$ I would check a box.

$\sqsupset$ The software filled the field for me.

Jother:

$\exists$ I don't know how I would specify the data with this form.

8a. What would you enter on the PCR form for the field labeled "Problem Area"?

8b. How would you specify the "Problem Area"on the PCR form?

Il would type it in.

$\beth$ I would select it from a drop-down list.

$\exists$ I would choose a radio button.

II would check a box.

$\square$ The software filled the field for me.

JOther:

I don't know how I would specify the data with this form.

9a. What would you enter for the Title of the PCR?

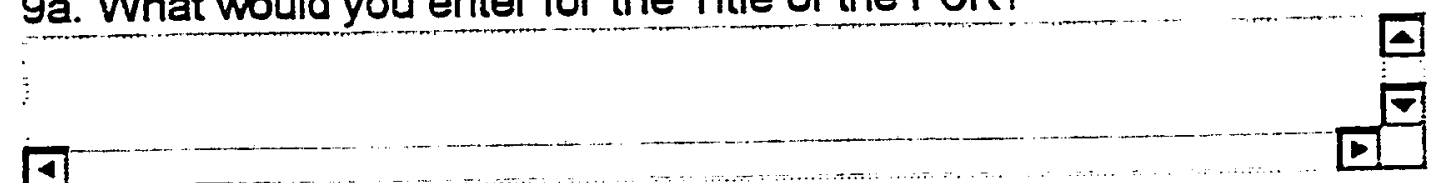

9b. How would you specify the "Title"on the PCR form? 
$\exists$ I would type it in.

$\exists$ I would select it from a drop-down list.

\lrcorner l would choose a radio button.

$\exists$ I would check a box.

$\sqsupset$ The software filled the field for me.

$\exists$ Other:

I don't know how I would specify the data with this form.

10a. What would you enter for the "Description" of the PCR?

a

10b. How would you specify the "Description"on the PCR form?

I would type it in.

Il would select it from a drop-down list.

Il would choose a radio button.

$\exists$ I would check a box.

$\exists$ The software filled the field for me.

$\exists$ Other:

JI don't know how I would specify the data with this form.

Please choose the best response to each of the following statements about the PCR form.

1. The objects and elements of the form are too crowded.

$\checkmark$ strongly disagree $O$ disagree $O$ neither agree strongly agree

2. The labels on the form are meaningful.

astrongly disagree o disagree $a$ neither 0 agree $S$ strongly agree

3. The colors on the form are used appropriately 
$O$ strongly disagree $O$ disagree $O$ neither $O$ agree $O$ strongly agree

4. The elements on this form are grouped together in a logical way.

$O$ strongly disagree $\mathrm{O}$ disagree $\mathrm{O}$ neither $\mathrm{C}$ agree $\mathrm{C}$ strongly agree

5. This form can do all the things I think I would need.

$O$ strongly disagree $O$ disagree $O$ neither $O$ agree $O$ strongly agree

$$
\begin{gathered}
\text { View FASB Form } \\
\text { (May take a while to load) }
\end{gathered}
$$

In the following scenario, you are required to update the FASB form to account for your time. The form is a simple mock-up so you are required to mentally walk through the steps that you would take to complete the tasks. You must account for your time for the past month. You have spent $20 \%$ more of your time on Vampire than last month. You spent the rest of your time doing development work for Alta. Read the questions below and fill-in your answers

Please read each question and fill in a short answer to each one and then check the method you would use to enter the data.1a. Would you be entering data for yourself, or someone else?

1b. How would you indicate who you were entering data for?

I w would type it in.

$\exists$ I would select it from a drop-down list.

$\exists$ I would choose a radio button.

Il would check a box.

$\exists$ The software filled the field for me.

Jother:

$\downarrow$ l don't know how I would specify the data with this form.

2a. How would you specify that you wanted to change the Vampire data?

$\square$

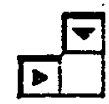


$2 b$. What method would you use on this form to first indicate that you wanted to change the Vampire data?

\lrcorner l would type it in.

II would select it from a drop-down list.

$\exists$ I would choose a radio button.

$\exists$ I would check a box.

The software filled the field for me.

$\exists$ Other:

$\exists$ I don't know how I would specify the data with this form.

3a. What is the percentage of time you would charge to Vampire? What method would you use

$3 b$. What method would you use to enter the new percentage of time charged to Vampire?

$\exists$ I would type it in.

$\exists$ I would select it from a drop-down list.

$\exists$ I would choose a radio button.

Il would check a box.

$\checkmark$ The software filled the field for me.

Jother:

Il don't know how I would specify the data with this form.

4a. What would you enter as the name for the rest of your time charges?

4b. How would you specify this new name to add to the data?

7 would type it in.

II would select it from a drop-down list.

1 I would choose a radio button.

JI would check a box.

$\exists$ The software filled the field for me.

JOther:

I I don't know how I would specify the data with this form.

5a. How would you describe the type of work you are doing with the new project?

5b. How would you specify this description? 
$\exists 1$ would type it in.

II would select it from a drop-down list.

\lrcorner would choose a radio button.

Jl would check a box.

$\exists$ The software filled the field for me.

Other:

I don't know how I would specify the data with this form.

$6 a$. What is the percentage of time you would charge to the new project?

6b. How would specify the amount of time you worked on the new project?

II would type it in.

1 I would select it from a drop-down list.

$\beth$ I would choose a radio button.

$\exists$ I would check a box.

$\square$ The software filled the field for me.

Other:

$\exists$ I don't know how I would specify the data with this form.

Please choose the best response to each of the following statements about the FASB form.

1. The objects and elements of the form are too crowded.

$O$ strongiy disagree $O$ disagree $O$ neither $O$ agree $r$ strongly agree

2. The labels on the form are meaningful.

strongly disagree $O$ disagree $Q$ neither $\circlearrowleft$ agree 0 strongly agree

3. The colors on the form are used appropriately.

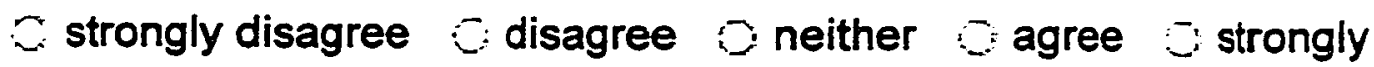
agree

4. The elements on this form are grouped together in a logical way. 
$O$ strongly disagree $O$ disagree $O$ neither $C$ agree $C$ strongly agree

5. This form can do all the things I think I would need.

$O$ strongly disagree $O$ disagree $O$ neither $O$ agree $O$ strongly agree

Which of the following best describes your job function?

CEngineer

Technical Publications

How long have you been performing your job function?

years

What is your primary computer platform?

Windows NT/95

Unix

Other:

Comments

If you would like to receive information on the results of this study please fill-in your email address. @EDA.com 


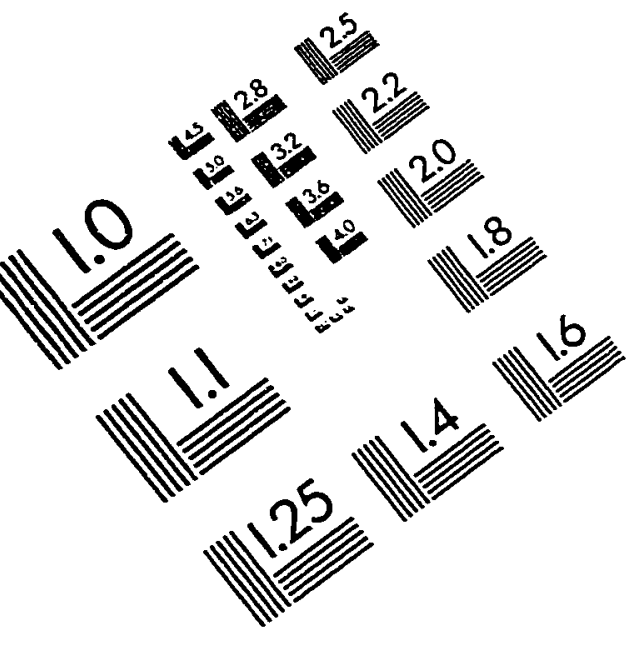

IMAGE EVALUATION
TEST TARGET (QA-3)
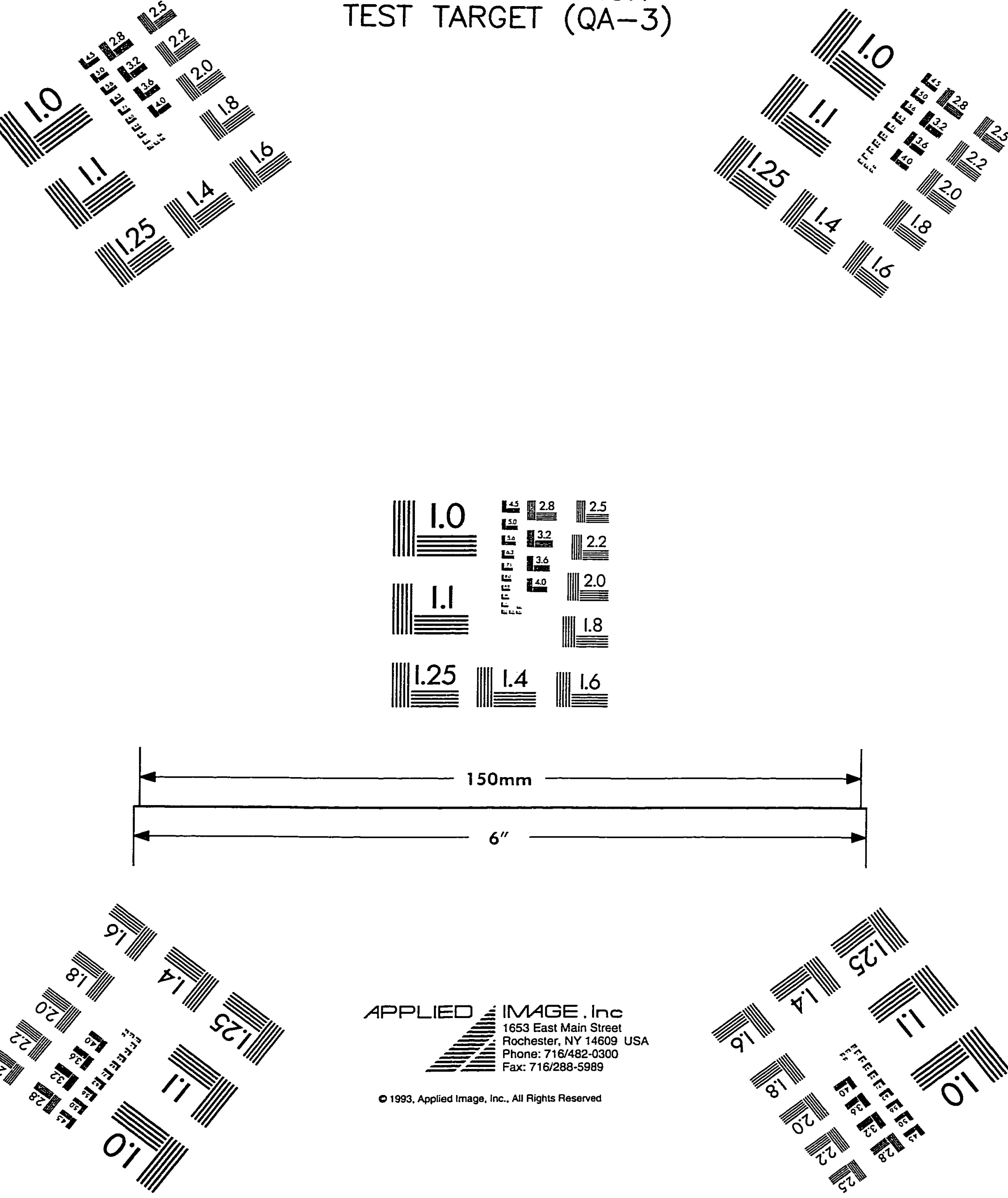